\title{
Loss of Patency of Side Branch
}

National Cancer Institute

\section{Source}

National Cancer Institute. Loss of Patency of Side Branch. NCI Thesaurus. Code

C119210.

A decrease in the openness of a side branch of a blood vessel. 